Journal of Research in Interprofessional

Practice and

Education

Vol. 3.3

February, 2014

\title{
Using Loose Coupling Theory to Understand Interprofessional Collaborative Practice on a Transplantation Team
}

\author{
Lorelei Lingard, MA, PhD; Allan McDougall, MA; \\ Mark Levstik, MD; Natasha Chandok, MPH, PhD; \\ Marlee M. Spafford, OD, PhD; \& Catherine Schryer, PhD
}

\begin{abstract}
Background: A central paradox dwells at the heart of interprofessional care: the tension between autonomy and interdependence. This report uses an ethnographic study to understand how this tension shapes collaborative practice on a distributed, interprofessional transplant team in a Canadian teaching hospital.

Methods \& Findings: Over four months, two trained observers conducted an ethnography through 162 observation hours, 30 field interviews and 17 formal interviews with 39 consented participants. Data collection and inductive analysis proceeded iteratively. Loose coupling theory was used as a resource to make sense of key themes. We describe the transplant team as a constellation made up of core, inter-service, and outside hospital dimensions. Next, we trace the nature of coupling activities within and across these dimensions of the team constellation, focusing on recurring communication challenges which can signal the relationship between autonomy and interdependence in collaborative acts.

Conclusions: We conclude that coupling is fluid and subject to human agency, and that the tension between autonomy and interdependence can be highly productive. Team members, including patients, may negotiate and construct their relations on an autonomy/interdependence axis for strategic purposes. Far from being trapped in a paradox, team members use autonomy and interdependence as resources to achieve complex goals in collaborative settings.
\end{abstract}

Keywords: Team communication; Interprofessional collaboration; Distributed teams; Ethnography; Organizational theory

\section{Introduction}

Interprofessional care and education are recommended, both globally and in the local context of our study, for best practices and improved patient outcomes [1,2]. A systematic review of interprofessional care interventions concluded that we need qualitative methods to provide insight into how these interventions influence collaboration and how improved collaboration contributes to changes in outcomes [3]. Yet, in the health sciences, a central paradox dwells at the heart of interprofessional

Journal of Research in Interprofessional Practice and Education (JRIPE)

Vol. 3.3

(C) 2014

Corresponding Author: Lorelei Lingard. Email: ilorelei.lingard@schulich!' uvo.cai care (IPC) and interprofessional education (IPE): the tension between autonomy and interdependence. Autonomy is the requirement for health professionals to make decisions as individuals. Interdependence is the requirement for health professionals to make decisions as part of a team or a larger system of care. Situated at the interface of the social and the cognitive [4], this paradox emerges in the IPC literature in ongoing theoretical and methodological dialogues. Despite evidence supporting the effectiveness of strong interprofessional collaboration for patient outcomes [5,6], critics assign these insights little more than rhetorical significance 
Loose Coupling Theory and IPC Research

Lingard, McDougall, Levstik, Chandok, Spafford, \& Schryer
Journal of Research in Interprofessional Practice and Education

Vol. 3.3

February, 2014 in light of continuing epistemological hegemony in professional roles and disciplinary hierarchies in health care settings $[7,8]$.

Additional tensions are found in terminological distinctions among multidisciplinary, interdisciplinary and transdisciplinary teams [9], and in the way teams, team processes, and team work are conceptualized and reified [10]. Should teams be categorized according to members' degrees of integration [11] as per operant philosophies of teamwork [12], or according to theoretical models of differentiation and integration of interpersonal and interorganizational elements [13]? A recent scoping review of interprofessional education, interprofessional practice, and interprofessional organization interventions further exhibited tensions in interprofessional vocabulary, but also elaborated a long-standing lack of linking empirical results with downstream patient and system outcomes [14].

Directly or indirectly, IPC scholarship explores how the tension between autonomy and interdependence makes the goal of effective collaborative practice both possible and problematic. This paradox between autonomy and interdependence was a strong emergent theme in an ethnography we conducted of a transplantation team, a methodology considered well suited for IPC and IPE research [15]. As we sought to deepen our understanding of this theme in the data, we turned to the organizational theory of loose coupling as an analytical resource. Recently taken up as a lens for studying multidisciplinary work in healthcare [16,17], loose coupling has promise not only for explaining how systems that seem to be in opposition can survive [18], but also for exploring the extent to which interprofessional collaboration in health care is viable "not only in spite of the loose linkage between professionals, but because of it" [19].

Using loose coupling theory as a starting point, this report contains our insights regarding how teamwork is possible in the face of the apparently paradoxical forces of autonomy and interdependence in a complex, distributed interprofessional team. Our analysis of recurring communication events explains how team member autonomy and interdependence are mediated by interactions in and between three team dimensions: core dimension, inter-service dimension and outside dimension.

\section{Methods}

\section{Research Questions}

As an ethnography, our study sought to describe and understand a particular social phenomenon. We began with the research question: How does a transplantation team do its work collaboratively across many temporal and spatial environments? Based on our past research, we were interested in tracing communication practices. As our fieldwork unfolded, this initial question was refined to reflect our growing sense of a set of improvisational strategies that team members draw on to face recurring collaborative challenges. Therefore, we expanded our research question: What are the recurring challenges to collaboration on the transplantation team? And how does the team improvise or adapt to changing environments in response to these? 
3

Loose Coupling Theory and IPC Research

Lingard, McDougall, Levstik, Chandok, Spafford, \& Schryer
Journal of Research in Interprofessional Practice and Education

Vol. 3.3

February, 2014

\section{Setting}

The study was approved by the university and hospital research ethics boards. Consented participants included 39 healthcare professional transplant team members. Inpatients were informed of the study by a patient care facilitator but were not consented, as they were neither directly observed nor interviewed. Ten outpatients were consented for observation of their pre-scheduled meetings with various team members. Because transplant teams in Canada are relatively few in each organ domain (e.g., heart, kidney, liver, lung), we refer generically to our study setting as a "transplant team," and refer to participants as medicine and surgery staff and trainees rather than delineating particular specialties, in order to preserve anonymity.

\section{Data collection}

Over four months, two trained researchers collected data from five sources: observations of daily team rounds and weekly selection rounds; observations of transplant assessments; individual shadowing of team members; spontaneous field interviews (brief clarifying discussions during observations); and formal, semistructured interviews. In total, 162 hours of observation, over 30 field interviews, and 17 formal interviews were conducted. Formal interviews were pre-scheduled; field interviews were conducted on an ad hoc basis based on participant invitation or an observer's request to shadow a team member. Observations included 34 daily team sit-down and walkabout rounds, and nine weekly selection rounds during which candidates for the organ wait list were discussed. Individual shadowing was conducted with 18 team members. Field interviews during individual shadowing were reconstructed in reflective, hand-written fieldnotes according to ethnographic convention [20]. During observations, researchers recorded standard, hand-written ethnographic fieldnotes [21].

Seventeen formal, semi-structured interviews were scheduled with a sample of team members representing most professions involved on the transplant team (e.g., medicine [attending and residents/fellows], surgery [attending and fellows], nursing, social work, transplant co-ordination, nutrition, physiotherapy). Semi-structured interviews were audio-recorded. The interview guide emerged through early analysis of the observational fieldnotes. During the first nine interviews, topics included communication strategies, everyday problem-solving in distributed care, and processes of learning team communication skills. The second phase of eight interviews used illustrative patient cases from the observational data set to prompt participants' reflections on recurring collaboration and communication challenges.

\section{Data analysis}

We began with a traditional inductive analysis process [21]. Fieldnotes, reflective memos, and interview transcripts were analyzed for emergent themes related to our main research questions: How does collaboration happen on the transplant team? What are the recurring communication practices that underpin this collaborative work? How are these practices responsive to recurring challenges to collaboration? 
4

Loose Coupling Theory and IPC Research

Lingard, McDougall, Levstik, Chandok, Spafford, \& Schryer

Journal of Research in Interprofessional Practice and Education

Vol. 3.3

February, 2014
Data analysis was an iterative process conducted alongside data collection, consistent with qualitative analytic approaches [22]. Thematic coding involved one researcher conducting "open coding" for emergent themes. Over a series of group meetings, this open coding was reviewed and refined by four other researchers, one of whom was an insider/collaborator from the transplant team. The refined thematic coding structure was then applied to the entire data set, using NVivo qualitative data analysis software. Thematic coding was verified for its resonance with the transplant team's experience through a series of key informant interviews and three return-of-findings focus groups, where thematic concepts were presented back to team stakeholders.

As thematic coding was summarized and explored, we began to explore theories that might serve as useful resources for interpreting our findings. We identified loose coupling theory as a useful framework for understanding how the team structure was related to their handling of recurring challenges to effective collaboration. After identifying the relevance of loose coupling theory to our data set, we applied loose coupling theory to explicate the processes in our findings.

\section{Loose coupling theory}

Weick [23] defined loose coupling as a situation in which elements of an organization are responsive but retain evidence of separateness and identity. Theories of loose coupling have seen most use in educational environments [18], but they have also been applied in research settings as diverse as law enforcement [24] and nursing [25]. Our interpretation of loose coupling follows the reconceptualization offered by Orton and Weick [26], who argue against simple descriptions of organizational systems as either tightly coupled systems that are "determinate, closed systems searching for certainty" or decoupled systems that are "indeterminate open systems expecting uncertainty" (p. 204). In defining a loosely coupled system, they explain that loosely reflects how a system's elements are subject to spontaneous changes and indeterminacy, while coupled reflects how a system's elements are linked and contain degrees of determinacy. System elements are further characterized by their "responsiveness," the ability of an element to respond to environmental changes, and their "distinctiveness," the independent role each element plays in its system. As Orton and Weick describe, "if there is responsiveness without distinctiveness, the system is tightly coupled. If there is distinctiveness without responsiveness, the system is decoupled. If there is both distinctiveness and responsiveness, the system is loosely coupled" (p. 205).

Orton and Weick find that the concept is often "reduced to a unidimensional variable" where loose coupling is portrayed as the endpoint of a coupling spectrum extending from tight at one extreme and loose at the other. Asserting that this unidimensional approach is "a simplification that should be resisted" [26], Orton and Weick instead advocate for a dialectical interpretation of coupling that captures "simultaneously open and closed, indeterminate and rational, spontaneous and deliberate" systems [26]. Dialectical loose coupling theory has the potential to advance teamwork typologies [11] and definitions [27], which have tended to be oriented toward "team as a stable state." As Bleakley, Bligh and Browne have argued 
5

Loose Coupling Theory and IPC Research

Lingard, McDougall, Levstik, Chandok, Spafford, \& Schryer

Journal of Research in Interprofessional Practice and Education

Vol. 3.3

February, 2014
[28], invoking Bauman [29], such unidimensional concepts of teams do not adequately grapple with the changeable and contextual nature of interprofessional teamwork [27]. Epistemologically congruent with this call, our dialectical interpretation defines loose coupling as an ongoing and evolving activity that may occur "among individuals, among subunits, among organizations, between hierarchical levels, between organizations and environments, among ideas, between activities, and between intentions and actions" [26].

Toward this end, Orton and Weick advocate methodologies such as ethnographies, case studies, and systematic observations that can yield such process insights. A good example explores the multidisciplinary system of breast cancer care [17]. Combining activity theory with loose coupling, Heldal considers the role of boundary objects ${ }^{1}$ in the integration of clinical disciplines in breast cancer care. The meaning of an object, like radiology film, if immutable or constant, can fortify disciplinary boundaries, causing looser coupling between radiology and oncology. By contrast, Heldal argues, negotiable meanings enable tighter coupling via interdisciplinary responsiveness.

We diverge from Heldal in resisting his assertion "that the benefits of multidisciplinary teamwork lie in a tighter coupling across professional boundaries" [17]. Rather than drawing general conclusions regarding the effectiveness of tightly coupled over loosely coupled systems, or vice versa, our work takes up Orton and Weick's call for researchers to conduct "descriptive" rather than "evaluative" work $[30,31]$ that explores the domains and patterns of coupling and decoupling in a system, toward understanding their effects in particular situations.

\section{Results}

We present findings related to two main descriptive foci: 1) a description of the transplant team as a constellation of connected yet autonomous units and 2) a description of the recurring communication events that signal shifting degrees of coupling within and across these units. For the current project, we describe these events as communication challenges, defined as observed instances where the team exerts visible effort through features such as vigorous debate, revisiting an issue from one meeting or day to another, or explicitly strategizing about how to achieve a collaborative goal. Communication challenges are prominent in our dataset, partly because they present themselves more readily to observers through the aforementioned features and partly because team members discuss them at length in both spontaneous and formal interviews.

We defined the transplant team as the core group of professionals who would meet daily or weekly to discuss transplant patients. But the transplant team is not a single group that is stable across time and situation. Rather, it is a constellation of intersecting units whose coupling (i.e., degree of autonomy or responsiveness) shifts according to particular collaborative situations. Our ethnographic data suggest that this team constellates into three broad dimensions of activity: a core dimension characterized by high responsiveness, where tight and loose coupling both occur; an inter-service dimension characterized by strong tension between autonomy and 
6

Loose Coupling Theory and IPC Research

Lingard, McDougall, Levstik, Chandok, Spafford, \& Schryer

Journal of Research in Interprofessional Practice and Education

Vol. 3.3

February, 2014 responsiveness, where recurrent communicative efforts are applied to maximize responsiveness and sustain loose coupling; and an outside hospital dimension characterized by minimal responsiveness and strong autonomy, where episodes of decoupling were found to occur. Within each of these dimensions of activities, sub-units exist and intersect according to the given clinical situation, creating an instability or unpredictability in the degree of coupling in the overall care system.

\section{The core dimension}

The core dimension is made up of healthcare professionals, transplant patients and patients' families. The core healthcare professionals meet every morning in a conference room for rounds and then walk through the inpatient ward to visit patients together. Presence at rounds was selected as a defining characteristic of core membership because it is a marker of regular work interactions, longstanding relationships with transplant patients and families, and in-depth knowledge of clinical and organizational issues on the team. The core group is fairly large relative to the number of patients with whom the team typically works. Along with patients and family members, the observed core group consisted of: 4 transplant specialists and 1-2 medical fellows ${ }^{2}$ specializing in the organ domain of this team, 1 nurse practitioner, 3 transplant surgeons and 2-3 surgical fellows, 1 dietician, 1 social worker, 2 physiotherapists, 1 pharmacist, 3 recipient co-ordinators and periodically a medical student. On any given morning, however, the core group was smaller, due to shift and on-call schedules: 8-12 healthcare professionals, including transplant specialists, transplant surgeons, allied health professionals, and physician trainees, gathered daily to review the status of and plans for inpatients.

Generally, roles within the health professional core were distinct but responsive, pervaded by a hierarchy that varied according to stages of the transplant process. For instance, transplant surgeons led the surgical care for patients immediately postoperatively, thus deciding the surgical management issues, such as the timing of drain removal, in daily discussions with the transplant specialists who would resume responsibility for the patient a few days post-transplant. Similarly, although team members' roles were interdependent, each professional applied distinctive expertise, and, as a group, they drew on one another strategically. For instance, a recipient coordinator might be called on to help a transplant specialist or transplant surgeon to communicate with a family with whom she has a longstanding relationship. This state of loose coupling in the core health professional group was common but not constant. Impending shifts in the balance of autonomy and responsiveness were particularly visible around the communication challenge of "cohesion," which we defined as instances in which core team members struggled to cultivate mutual awareness and shared expectations regarding key patient care issues.

Cohesion challenges often became visible through the expression of clinical differences of opinion. An example was a disagreement, revisited repeatedly, between a transplant specialist and a transplant surgeon about when a particular post-transplant patient should be discharged to his home hospital. Rarely, cohesion challenges led to a complete loss of responsiveness, such as when a health professional acted 
Loose Coupling Theory and IPC Research

Lingard, McDougall, Levstik, Chandok, Spafford, \& Schryer

Journal of Research in Interprofessional Practice and Education

Vol. 3.3

February, 2014

\section{Journal of Research in Interprofessional Practice and Education}

on their differing interpretations of plans without informing colleagues:

Coordinator 2: Is he still active [on the waiting list]?

Physician 3: Yes.

Coordinator 1: Nope. Surgeon 3 took him off.

Physician 3: Nobody told me. (Fieldnotes, Day 25)

The transplant surgeon's "delisting" of the patient reflects a significant increase in autonomy and decrease in responsiveness within the health professional core. One might interpret the event as a momentary decoupling of the collaborative system within the core team. The disagreement itself is not what decouples the members of the core team from one another in this situation, as we observed other instances of clinical disagreement in which autonomy and responsiveness were both in play. Rather, the complete autonomy of the action of taking the patient off the list is what radically alters the nature of the coupling. Time pressures, hierarchy, and clinicallegal responsibility are understood to limit communication in some circumstances, but, as one recipient coordinator reflected, "When it is not discussed, then it just feels like disrespect."

Patients and families are included in the core dimension of the transplant care constellation. Successful transplantation requires not only expert care providers, but also patients who can care for the organ they receive by complying with lifelong drug regimens and lifestyle restrictions. Patients must also demonstrate access to a social support system during the arduous process of waiting for and, for some, living with a donated organ. Underpinning this strong sense of partnership between providers and patients is the principle of "stewardship," the responsibility of both health professionals and patients to ensure donated organs are used appropriately, given the scarcity of this resource. Stewardship sets up a highly responsive relation between patients and core health professionals:

I think in the case of any sort of a transplant, if you don't have a partner in the patient, then you really can't do the transplant. And I would view that as a contraindication to proceeding, even though we know this type of treatment saves lives and gives people quality of life. So I think the patient cooperation, insight, judgement, willingness to comply, all of those things are really critical to our decision making, to whether we can help them as far as transplant or not. (Physician 2, interview)

With such a strong requirement for responsiveness, many collaborative activities between patients and core health professionals have characteristics of tight coupling. For instance, without exception, patients with a history of addiction are required to be abstinent for six or more months following an addiction counselling program. Such rules position patients as necessarily highly responsive; when they are not, they are ineligible to remain in the care constellation. However, patients' clinical conditions are complex, their social situations unique, and their behaviours not always predictable. These factors rebalance distinctiveness and responsiveness in the core 
8

Loose Coupling Theory and IPC Research

Lingard, McDougall, Levstik, Chandok, Spafford, \& Schryer
Journal of Research in Interprofessional Practice and Education

Vol. 3.3

February, 2014 dimension, as seen when core health professionals work with patients to tailor clinical regimens (such as dietary expectations) to their individual circumstances.

With loose coupling comes a move away from strict rules and toward negotiation of perspectives. In our analysis, such negotiation is visible in the communication challenge of "alignment," which we defined as instances of tension in coordinating patients' and core health professionals' expectations of how care will unfold. A pervasive example of alignment challenges relates to the waiting period. A recipient coordinator explained:

It can't be totally public and transparent where patients stand on the waiting list and how listing decisions are made. That is a bone of contention for patients. Feeling like, "well, obviously I must be the sickest person because I am really suffering," and no doubt they are, but it's not possible for them to have a sense of how sick other people may be. And it's not realistic to think anyone would say, "Well clearly that person is way sicker than me, so they should go first." (Coordinator 3 , interview)

Patients can only experience their own waiting, often accompanied by personal suffering that extends to their loved ones. While many listed patients understand the waiting list process and empathize with the rest of the patients on the list, health professionals are privy to the details of clinical experiences of the cohort of listed patients. Distinctiveness is further intensified by each group having unique definitions of suffering. For patients, suffering is subjectively experienced; for providers, it is objectively appreciated. For instance, during a pre-transplant interview between a patient and an allied health professional, a patient's experience of illness contrasted starkly with the measurement of their disease state. After the health professional commented to the patient, "Your numbers look really good," he then asked about quality of life, to which the patient replied, "Crap!" In response, the health professional asked, "On a scale of one to ten? [Where one is the lowest]," to which the patient replied, "One!" The social worker asks the patient to objectify their subjective reporting of "Crap!" by selecting a point on a numerical scale, a standard practice in medicine. Along with providing some sense of the patient's experience by associating their pain with a measurable number, this is also an effort at coupling in order to reconcile two distinctive definitions of suffering.

\section{The inter-service dimension}

Transplant care is not achieved by the core dimension alone; it requires collaborative activities with other groups in the hospital, which we have termed the "interservice" dimension of the transplant care constellation. This dimension is made up of healthcare professionals who are necessary for the successful enactment of particular practices in transplantation, but whose relationship to the patient, in terms of familiarity and responsibility, is much looser. The inter-service dimension includes a number of sub-groups (i.e., clinical specialties such as cardiology and ophthalmology) who consult on transplant patients, and organizational units (i.e., 
9

Loose Coupling Theory and IPC Research

Lingard, McDougall, Levstik, Chandok, Spafford, \& Schryer
Journal of Research in Interprofessional Practice and Education

Vol. 3.3

February, 2014 intensive care) who temporarily admit all transplant recipients and provide critical care for patients experiencing severe illness and difficult post-operative recovery. Core health professionals initiate collaborative interactions with the inter-service dimension through consultation requests for expertise and resources.

In principle, the consultation system is loosely coupled: an individual, autonomous expert (e.g., a pathologist) responds to a request to apply her expertise in a clinical situation for which another autonomous expert (e.g., a core transplant specialist from the transplant team) is primarily responsible. However, several factors influence the loosely coupled relations of consultations across the core and inter-service dimensions. One factor is a service's experience with transplantation:

Groups that are a little more tightly associated with transplant and/or the outcomes, so radiology, pathology, for the most part they're very easy to communicate with, they understand our needs and vice versa, and over time it's been relatively smooth to communicate what we need and when we need it by, and they've been very accommodating. Services that we don't often mingle with, so cardiology's one of those services, right, we don't consult cardiology very often on our patients, so when we do there's a thinking that they don't necessarily understand our patient mix or what we're asking or why we're asking it. So there's a little more effort to sort of do the background with them and sort of explain, you know, "This is why we've called you." (Physician 1, interview)

This comment emphasizes the central role of communication in coupling: responsiveness is cultivated by spending "a little more effort." While this strategy is often effective, it can be complicated by sub-specialization. For instance, in one situation a carefully explained cardiology consult request was translated by the first responding cardiologist to an arrhythmia consult, introducing another cardiology subspecialty and diluting the core members' original message about "what we're asking or why we're asking it."

Just as a service's experience with transplant can influence coupling, so too can the experience of individual specialists. As one transplant specialist explained, "We have to call [Transplant Anesthesiologist 1] and try to get him or [Transplant Anesthesiologist 2] to come up, because those are the two decision-makers down there." Here, loose coupling affords the core team a degree of flexibility: because there are no explicit rules about which specialists must be consulted, the core health professionals can streamline their consultation requests by targeting specific transplant anesthesiologists.

Targeted consultations tighten the coupling between the core team and an interservice unit by increasing feedback and attention, two features that directly affect organizational connections [30,31]. Feedback refers to when people learn about the effects of their actions: the sooner a response is received, the tighter the coupling. Attention refers to the constancy of focus: more constant attention means more stability, while attention shifts mean more variability. Consultation, as a collaborative 
10

Loose Coupling Theory and IPC Research

Lingard, McDougall, Levstik, Chandok, Spafford, \& Schryer
Journal of Research in Interprofessional Practice and Education

Vol. 3.3

February, 2014 practice, is inherently predicated on weak organizational connections because many consultants never learn of the effects of their consultative advice. Consultations are, by their nature, fraught with attention shifts. Therefore, calling on a small cadre of "more tightly associated" specialists effectively maximizes feedback and attention, thus strengthening organizational connections and reducing the likelihood of misunderstandings and repeat consultations.

The existence of dual responsibilities for consulting specialists also influences coupling between the core and inter-service dimensions. Cardiologists, for instance, have their own cardiology inpatients whose care occupies much of their working day. Cardiologists fit in requests for consultations around primary cardiology duties. The tension between the responsiveness of the consulting service and their autonomous clinical workload is enacted in different ways. In the face of this variability, core members of the transplant team strategize to increase responsiveness by, again, targeting particular consultants. As one team member advised a physician trainee prior to embarking on a consultation request to interventional radiology: "If you fail with [Radiologist 1], go to [Radiologist 2], he was going to do a similar [procedure] for us last year" (Fieldnotes, day 2).

Coupling is further complicated when more than one service is consulted on the same clinical situation. Recalling a consultation request in which multiple clinical services were drawn into the decision-making, one core health professional explained:

[The core team physicians] and anesthesia felt that a patient needed a left-sided heart catheter prior to listing for ... transplant, and cardiology disagreed with that and so the compromise between all 3 services is to order a CT angiogram, which is performed in radiology. And then the radiologists wanted the heart rate to be much better controlled prior to doing the CT angiogram because they felt that the false-positive rating would be too high with a high heart rate, and so they didn't want to do the scan. (Fellow 1, interview)

In this example, each expert perceives the situation differently, and, because that perception is rooted in their autonomy as "experts," each is reluctant to relinquish that autonomy in favour of responsiveness. Coupling is about perceptions, not just professions. In such situations, the core team exerts considerable effort to reconcile incompatibilities between the technical pressures (i.e., expertise, ways of doing things, perceptions of risk) within each specialty's boundary and the institutional pressure to advance with an informed decision for a transplant patient. Core team members work to achieve a shared assessment across these autonomous specialties regarding the perception of "what's low risk, what's too high risk, what's acceptable risk, and how do we define that" (Physician 1, interview). In such effortful communications, responsiveness is identified as an explicit goal, rather than taken for granted.

The outside dimension

The "outside" dimension of the transplant team constellation represents instances in 
Loose Coupling Theory and IPC Research

Lingard, McDougall, Levstik, Chandok, Spafford, \& Schryer
Journal of Research in Interprofessional Practice and Education

Vol. 3.3

February, 2014

\section{Journal of Research in Interprofessional Practice and Education}

which the core group must engage individuals and organizations from outside their own hospital. Collaborative practices here include negotiations with community supports (e.g., home hospitals) for inpatients nearing discharge, contact with other transplant centres for the purposes of transferring patient information, and requests from referring individuals (e.g., family physicians) or organizations (e.g., community hospital emergency departments) seeking to have patients assessed or transferred to the core health professional team.

Collaborative activities between the "core" and "outside" dimensions tend to be only tenuously coupled, characterized by minimal responsiveness, strong autonomy, and recurring episodes of decoupling. For example, receiving referrals and admitting patients from their home hospitals is a common occurrence for the transplant team. Coupling with the outside dimension is enacted predominantly through telephone conversations between core transplant specialists and physicians from outside hospitals. One core medical fellow explains some of the complexities around these interactions with outside professionals:

When I'm on call I receive lots of calls from outside. Lots of those questions are standard of care ... basic questions, and if they ask for transfer of care of course we refuse that. Now, there are some legitimate reasons for calling, and then we'll accept transfer but ... sometimes you get a mixed message. They tell you the patient is really sick and needs to be transferred, blood pressure is low and so ... we bring the patient in and sometimes they're clear about what they're doing and they're helpful and we give them the guidance just to continue doing what we ask them to do and they do it. So it's very variable. And sometimes ... they're just trying to get that patient off of their service. (Fellow 2, interview)

Core members depict repatriation, the process of transferring patients back to a bed in their home hospital, as one of the main communication challenges with the outside dimension. For example, in the case of a patient the team believed did not require a bed on the transplant unit, two physicians discussed their frustration at a home hospital's inability to readmit the patient:

Physician 3: Why is [the patient] still here?

Physician 1: We have to do something about this because repatriation doesn't work ... I called [X] ... then I called [the recipient coordinator] and they called $[\mathrm{X}] \ldots$ then I called and left a voicemail for bed management.

Physician 3: Nobody wants [the patient] ...

Physician 1: The discharge summary was written [five days ago]. (Fieldnotes, day 29)

Patients are sometimes accepted for assessment by the transplant service under the expectation that a bed will be held for them in their home hospital. In some cases patients are admitted, do not require transplant's speciality services, but can- 
Loose Coupling Theory and IPC Research

Lingard, McDougall, Levstik, Chandok, Spafford, \& Schryer
Journal of Research in Interprofessional Practice and Education

Vol. 3.3

February, 2014

\section{Journal of Research in Interprofessional Practice and Education}

not be readmitted to their home hospital. Such a situation leaves Physician 3 feeling that "nobody wants" the patient.

According to one core health professional, a formal repatriation process had been established to improve integration across the boundary between core team and home hospital; however, that process was more symbolic of tighter coupling than an actual improvement in responsiveness between hospitals:

[Home Hospital A] is notorious for this type of problem, where, even though they know the patient, all of a sudden they don't know the patient anymore. ... This hospital has, because of the bed pressures here, has put this repatriation system in place, which was supposed to get the docs off the phone. So, you tell the bed admin people here that you've got a person that goes back to [Home Hospital A] ... And they're supposed to contact administration in [Home Hospital A] and co-ordinate a bed, get a physician there to accept, and then admin to admin says "It's good to go" and he's gone ... This was supposed to be great; I'll tell you, it just hasn't worked ... it's a very big, upsetting problem. (Surgeon 1)

As this account implies, there is a sense that home hospitals may use the inefficient repatriation process as a delaying tactic - "all of a sudden they don't seem to know the patient anymore." Accordingly, the repatriation communication process may function as a simultaneous enactment of responsiveness and autonomy by which the home hospital uses a loosely coupled system to delay the patient's repatriation to the institution.

In some instances, the core team takes advantage of loose coupling to behave in ways that acknowledge the principle of interdependence while simultaneously asserting their autonomy as the experts in caring for these complex patients. For example, they may prepare "cookbook" management plans to more tightly couple the care practices at the home hospital with their own expectations. In other cases, they may delay discharge of a patient who is, by most markers, ready for repatriation when the core team doubts the expertise at the home hospital is sufficient:

We do keep [patients from City B] here a lot longer than we otherwise would because we want everything to be as good as possible ... there are a few places like that where we will keep folks here for longer, for their best interest. (Physician 1, interview)

In such cases, the core team has judged the coupling between its care plan and that likely to be implemented by the home hospital to be problematically autonomous. As one core transplant surgeon explained: "I suppose that might be the greatest challenge ... the fact that these patients are a far distance away and they're not at the transplant centre ... And how much we trust the local doctors to do things that we want, would want done, or how to notify us." Coupling was tighter with a few home hospitals with which there was an established history of shared practices and regular communication: with these outside physicians, who "email us 
Loose Coupling Theory and IPC Research

Lingard, McDougall, Levstik, Chandok, Spafford, \& Schryer

Journal of Research in Interprofessional Practice and Education

Vol. 3.3

February, 2014 all the time and they communicate, they come to conferences, they phone in ... we don't mind sending patients up there because we know if there's an issue or a problem they have easy access to us" (Physician 1, interview).

What is initially a geographic challenge of distance is exacerbated by contradictory pressures to both enable timely discharge and ensure safe care. The paradox this creates for the core team is sometimes resolved by strategically decoupling the outside from the inside. From the outside, routine steps toward repatriation carry on, including preparing the patient for discharge through escalating physical therapy tasks and pharmacist education. On the inside, however, the core team acknowledges to themselves that they have no intention of discharging in the "normal" timeframe, and they delay the discharge.

Loose coupling between the core team and outside hospital creates opportunities for both groups to strategically seek greater responsiveness, or greater autonomy, between their units. Further, in a given clinical situation, one group may seek greater responsiveness while the other resists it, providing insight into the organizational tensions that complicate collaborative practice in distributed care settings. We observed patients strategically using the loose coupling between core team and outside hospitals to their own ends. For instance, inpatients sometimes sought to reduce the interdependence or connectedness between core and outside health professionals. One patient's mother argued to delay repatriation because she and her son "felt safer" as a core team inpatient, invoking the distinctiveness of the expertise available in the core team setting. A pre-transplant patient asserted the connectedness of core and outside dimensions, directly contacting the core on-call medical fellow from home to request an emergency interventional procedure, rather than being treated at his local emergency room. Core team members recognized this strategy; one recipient coordinator explained that it originated in patients feeling both a sense that local hospitals do not enjoy caring for them, and that the core team was best equipped to respond to their needs.

\section{Discussion}

Our ethnography of a transplant team illustrates Orton and Weike's dialectical premise that coupling is not a state but an activity. In the distributed care constellation we have described, which is made up of the core team, inter-service, and outside activity dimensions, coupling varies according to which dimensions are in play in a given collaborative situation. Coupling patterns (i.e., regularities in the relationship between responsiveness and autonomy) are visible within each dimension (Table 1); however, these by no means suggest that all collaborations within a dimension reflect a particular point on a "spectrum" of coupling. Rather, coupling is fluid and subject to human agency; it is managed, negotiated and socially constructed by individuals seeking particular effects in particular situations.

Communication events play a central role in coupling; therefore, we have used observable communication challenges in our data as evidence of coupling efforts, as signals of the relationship between responsiveness and autonomy in daily collaborative acts. Our results foreground the ways in which the responsiveness-auton- 
Loose Coupling Theory and IPC Research

Lingard, McDougall, Levstik, Chandok, Spafford, \& Schryer
Journal of Research in Interprofessional Practice and Education

Vol. 3.3

February, 2014
Table 1:

\section{Coupling across the dimensions of the transplant care constellation}

\begin{tabular}{|c|c|c|c|}
\hline Team dimension & Coupling patterns & Responsiveness & Autonomy \\
\hline Core dimension & Loose \& tight & High & Low \\
\hline $\begin{array}{l}\text { Inter-service } \\
\text { dimension }\end{array}$ & Loose & $\begin{array}{l}\text { Tension with } \\
\text { autonomy }\end{array}$ & $\begin{array}{l}\text { Tension with } \\
\text { responsiveness }\end{array}$ \\
\hline Outside dimension & Loose \& decoupled & Low & High \\
\hline
\end{tabular}

omy relation, or axis, of coupling is both negotiated and constructed in the transplant team constellation. It is negotiated when core team members, recognizing the high autonomy of consulting services, aim to maximize feedback and attention through their targeted, repeated use of particular consultants who grow increasingly knowledgeable about and responsive to the transplant context. It is constructed when patients and families behave as though there is tight coupling between core and outside dimensions, treating the core team as if they are interchangeable with a local emergency room and, consequently, creating a tighter coupling than actually exists.

Importantly, not all the negotiations and constructions of the responsivenessautonomy axis seek to increase responsiveness toward tighter coupling; some work to loosen the system, or even to decouple it. For example, at the interface of the core team and outside dimensions, both groups use a loosely coupled system of transferring patients between hospitals to achieve particular goals: the core team to retain patients they do not feel safe discharging to the home hospital, and the home hospital to delay repatriating patients that they may not have the resources (technical or financial) to adequately support.

These results suggest a few important implications. The first echoes Weick's assertion that "a loosely coupled system is not a flawed system. It is a social and cognitive solution to constant environmental change" [31]. Overall, the transplant care constellation is a loosely coupled system in which members act collaboratively in ways that both increase and decrease responsiveness as they seek to achieve particular goals. With this loosely coupled system, instances of tight coupling and of decoupling emerge. And while encountering a lower degree of responsiveness than expected across the three dimensions creates frustration for core team members, we would not conclude, as did Heldal [17], that tighter coupling equates to better collaboration. Rather, we contend that the relationship between coupling and effective collaborative, patient-centred care is a complicated and situated one. Actions that increase responsiveness (i.e., that tighten coupling) are not necessarily required for collaborative, patient-centred care. Certainly tighter coupling, such as the core team achieves through targeted consultation requests, may sometimes be in the best interest of effective collaborative care. But in other situations, loose coupling may be more desirable due to the flexibility it offers for subtly and strategically managing 
15

Loose Coupling Theory and IPC Research

Lingard, McDougall, Levstik, Chandok, Spafford, \& Schryer

Journal of Research in Interprofessional Practice and Education

Vol. 3.3

February, 2014 competing goals, such as timely discharge versus purposefully delayed discharge, all with the intent of patient care and safety.

Past research in loose coupling has highlighted the importance of such flexibility, suggesting that individuals engage in practices that simultaneously, and paradoxically, enact responsiveness and autonomy as they work to reconcile incompatibilities between institutional pressures (those outside a professional boundary) and technical pressures (those within). For instance, Manning's description of police organizations' joint tasks of filtering and responding to emergency calls exemplifies the simultaneous enactment of tight and loose coupling practices in the face of a high volume of incoming calls [24]. Similarly, Covaleski and Dirsmith's study of how effective nurse administrators alternately adopt "budget masks" to communicate with hospital administrators and "clan masks" to communicate with nurses demonstrates a form of loose coupling between hierarchical levels that helps nurses to negotiate the impact of cost controls [25]. We agree that the flexibility afforded by loose coupling seems to be important, as it allows members in the care constellation to increase autonomy or responsiveness strategically, in ways that help them to achieve goals.

Flexibility, however, entails a certain degree of unpredictability, which can create frustration for those trying to work within a system. We observed many instances in which core team practitioners were frustrated or distressed by not encountering anticipated levels of responsiveness in patients, families, and other care providers in the inter-service and outside dimensions. And, although practitioners discussed these frustrations with learners, they rarely talked explicitly about their expectations and strategies for achieving coupling in their collaborative activities. Furthermore, as Weick points out, systems in which autonomy and responsiveness fluctuate can be inefficient because there are minimal rules and routines forcing integration of practices. At the same time, however, loosely coupled systems may be more effective when assessed against criteria that index flexibility, ability to improvise, and capability for self-design [30]. When learners are present, however, their ability to decode the loosely coupled system will rely heavily on explicit discussion, which we saw only rarely in our observations.

At what point, though, does loose coupling become decoupling? We have described a few instances in which collaborative activities appeared to become decoupled, interpreting these as "momentary decouplings," largely because ensuing collaborative activities appeared to re-introduce responsiveness into the system. Perhaps these moments of decoupling offer opportunities for educators to find new ways to enhance training programs in fast-paced clinical/academic settings. Our own and others' research $[32,33]$ suggests that collaboration is commonly learned non-formally and tacitly rather than explicitly. It may be that momentary decouplings could provide particularly vivid instances where clinical teachers could point out the factors influencing decoupling and reflect on their strategies to achieve loose coupling. Such discussions could be a powerful mode of influencing learners' understandings of how the team is coupled or decoupled, and why. Future research should consider those factors that distinguish loose couplings from decouplings, 
Loose Coupling Theory and IPC Research

Lingard, McDougall, Levstik, Chandok, Spafford, \& Schryer
Journal of Research in Interprofessional Practice and Education

Vol. 3.3

February, 2014

\section{Journal of Research in Interprofessional Practice and Education}

characterize the communication strategies that are involved in converting into and out of decoupled activities, and identify effective ways of using these patterns to help learners participate effectively in collaborative teams.

\section{Conclusion}

We opened this report by invoking the central paradox at the heart of IPC: the tension between autonomy and interdependence. Intriguingly, our results suggest that this can be a highly productive tension, and that team members (as well as patients) may in fact negotiate and construct their relations on an autonomy/interdependence axis for strategic purposes. Far from being trapped in a paradox, team members use autonomy and interdependence as resources to achieve their goals in collaborative settings. Building on this study, the conclusions of which are constrained by design features, including a focus on a single team in a Canadian healthcare delivery context, future research exploring coupling activities on different clinical teams in diverse organizational contexts will be required to explore the transferability of these findings and to refine loose coupling theory to account for a range of collaborative practices in healthcare. Finally, future work applying loose coupling theory to interprofessional education settings could potentially deepen our understanding of how the autonomy/interdependence tension influences IPE practices and initiatives.

\section{Acknowledgments}

The authors would like to thank the Social Sciences and Humanities Research Council of Canada (Award \#410-2008-0232) for their financial support. Dr. Lingard is also supported as a Western University Department of Medicine Program of Experimental Medicine (POEM) Scientist. The authors would also like to thank the transplant team members who agreed to participate in and provide feedback on this research.

\section{Notes}

1. Objects or concepts that connect different groups and mediate social/professional transactions.

2. Fellows are advanced physician-trainees focusing on transplantation specialty certifications. Fellows were either medical fellows (trainee internal medicine physicians) or surgical fellows (trainee surgeons).

\section{References}

1. Greiner, A.C., \& Knebel, E. (2003). Health professions education: A bridge to quality. Washington, DC: National Academies Press.

2. Health Force Ontario. (2010). Implementing interprofessional care in Ontario. Toronto: Government of Ontario.

3. Zwarenstein, M., Goldman, J., \& Reeves, S. (2009). Interprofessional collaboration: Effects of practice-based interventions on professional practice and healthcare outcomes. Cochrane Database of Systematic Reviews, 8, CD000072.

4. Soubhi, H. (2010). The social and the cognitive in professional interactions: The "interprofessional intelligence" hypothesis. Journal of Research in Interprofessional Practice and Education, 1, 85-87.

5. Lingard, L., Whyte, S., Espin, S., Baker, G.R., Orser, B., \& Doran, D. (2006). Towards safer interprofessional communication: constructing a model of "utility" from preoperative team briefings. Journal of Interprofessional Care, 20, 471-483. 
17

Loose Coupling Theory and IPC Research

Lingard, McDougall Levstik, Chandok, Spafford, \& Schryer
Journal of Research in Interprofessional Practice and Education

Vol. 3.3

February, 2014
6. Baggs, J.G., Schmitt, M.H., Mushlin, A.I., Mitchell, P.H., Eldredge, D.H., Oakes, D., \& Huston, A.D. (1999). Association between nurse-physician collaboration and patient outcomes in three intensive care units. Critical Care Medicine, 27, 1991-1998.

7. Coombs, M., \& Ersser, S.J. (2004). Medical hegemony in decision-making-a barrier to interdisciplinary working in intensive care? Journal of Advanced Nursing, 46, 245-252.

8. McCallin, A. (2005). Interprofessional practice: learning how to collaborate. Contemporary Nursing, 20, 28-37.

9. Paul, S., \& Peterson, C.Q. (2002). Interprofessional collaboration: Issues for practice and research. Occupational Therapy in Health Care, 15, 1-12.

10. McCallin, A. (2001). Interdisciplinary practice-a matter of teamwork: an integrated literature review. Journal of Clinical Nursing, 10, 419-428.

11. Ovreteit, J. (1997). Planning and managing interprofessional working and teams. In J. Ovretveit, P. Mathias, \& T. Thompson (Eds.), Interprofessional working for health and social care (pp. 9-33). London: MacMillan Press.

12. Freeman, C.M.N.R.M. (2000). The impact of individual philosophies of teamwork on multi-professional practice and the implications for education. Journal of Interprofessional Care, 14, 237-247.

13. Willumsen, E. (2008). Interprofessional collaboration-a matter of differentiation and integration? Theoretical reflections based in the context of Norwegian childcare. Journal of Interprofessional Care, 22, 352-363.

14. Reeves, S. (2011). A scoping review to improve conceptual clarity of interprofessional interventions. Journal of Interprofessional Care, 25, 167-174.

15. Conn, L.G. (2010). Using ethnographic methods to understand change in interprofessional practice. Journal of Research in Interprofessional Practice and Education, 1, 301-303.

16. Schuhmann, R. (2005). The enterprise of public administration: scholarship as a loosely coupled system. Public Administration and Management: An Interactive Journal, 9, 45-67.

17. Heldal, F. (2010). Multidisciplinary collaboration as a loosely coupled system: integrating and blocking professional boundaries with objects. Journal of Interprofessional Care, 24, 19-30.

18. Koff, N.A., \& DeFriese, A.M. (1994). Loosely coupled systems as a conceptual framework for interdisciplinary training. Educational Gerontology, 20(1), 1-13.

19. D’Amour, D., Ferrada-Videla, M., San Martin, R.L., \& Beaulieu, M.D. (2005). The conceptual basis for interprofessional collaboration: core concepts and theoretical frameworks. Journal of Interprofessional Care, 19, 116-131.

20. Sanjek, R. (1990). Fieldnotes: The makings of anthropology. Ithaca: Cornell University Press.

21. Hammersley, M., \& Atkinson, P. (1995). Ethnography: Principles in practice. London: Routledge.

22. Denzin, N.K., \& Lincoln, Y.S. (2011). The Sage Handbook of Qualitative Research. Thousand Oaks: Sage.

23. Weick, K.E. (1976). Educational organizations as loosely coupled systems. Administrative Science Quarterly, 21, 1-19.

24. Manning, P.K. (1982). Producing drama: symbolic communication and the police. Symbolic Interaction, 5, 223-241.

25. Covaleski, M.A., \& Dirsmith, M.W. (1983). Budgeting as a means for control and loose coupling. Accounting, Organizations and Society, 8, 323-340.

26. Orton, J., \& Weick, K. (1990). Loosely coupled systems: a reconceptualization. Academy of Management Review, 15, 203-223.

27. Payne, M. (2000). Teamwork in multiprofessional care. Chicago: Lyceum Books.

28. Bleakley, A., Bligh, J., \& Browne, J. (2011). Medical Education for the Future: Identity, power and location. Dordrecht: Springer Science+Business Media B.V.

29. Bauman, Z. (2007). Liquid times: Living in an age of uncertainty. Cambridge: Polity Press.

30. Weick, K.E. (2000). Management of organizational change among loosely coupled elements. In Making sense of the organization, (pp. 380-403). Malden: Blackwell Business.

31. Weick, K.E. (2000). Sources of order in underorganized systems: Themes in recent organizational theory. In Making sense of the organization, (pp. 32-56). Malden: Blackwell Business.

32. Pollard, K. (2008). Non-Formal learning and interprofessional collaboration in health and social care. Learning in Health and Social Care, 7, 12-26.

33. Lingard, L., Espin, S., Evans, C., \& Hawryluck, L. (2004). The rules of the game: Interprofessional collaboration on the intensive care unit team. Critical Care, 8, R403-408. 